1 Int. J. Global Warming, Vol. 18, No. 1, 2019

\title{
2 A framework for predicting the effects of climate change on the annual 3 distribution of Lyme borreliosis incidences
}

4 Ákos Bede-Fazekas*

5 Institute of Ecology and Botany,

6 MTA Centre for Ecological Research,

7 Alkotmány u. 2-4.,

8 H-2163 Vácrátót, Hungary

9 and

10 GINOP Sustainable Ecosystems Group,

11 MTA Centre for Ecological Research

12 Klebelsberg Kuno u. 3.,

13 H-8237 Tihany, Hungary

14 Email: bede-fazekas.akos@okologia.mta.hu

$15 *$ Corresponding author

16

Attila J. Trájer

18 Department of Limnology,

19 University of Pannonia,

20 Egyetem u. 10.,

21 H-8200 Veszprém, Hungary,

22 Email: attila.trajer@mk.uni-pannon.hu

Abstract: Global climate change is predicted to affect both the spatial and annual distributions of vector-borne diseases. Tick-borne diseases are particularly sensitive to the changing climatic conditions. Modeling them is, however, challenging due to the input-intensity of these models. A framework with low number of inputs (easily accessible weekly temperature data and week numbers) on modeling the seasonality of Lyme borreliosis incidences is presented. The modelling framework enables predicting the annual distribution of Ixodes ricinus tick's biting activity and Lyme borreliosis in two cascading phases, incorporating a population dynamics approach. The model is calibrated for Hungary as a case study, for the period of 1998-2008, using tick-borne encephalitis series as a proxy for biting activity. Prediction to the future period of 20812100 is also provided. Climate change may significantly alter both the annual distribution of $I$. ricinus activity and that of the Lyme borreliosis incidences. The currently unimodal annual distribution of Lyme borreliosis is predicted to become bimodal with a long summer pause and a spring maximum shifted 8 weeks earlier.

Keywords: Lyme borreliosis; climate change; Ixodes ricinus; tick-borne encephalitis; prediction

Biographical notes: Ákos Bede-Fazekas is MSc in landscape architecture, BSc in software development, $\mathrm{PhD}$ in agricultural engineering sciences, and research fellow at Hungarian Academy of Sciences (MTA). His main research interest is in predictive ecological modeling in $\mathrm{R}$ statistical software and the impact of climate change. 
46 Attila J. Trájer is doctor of medicine (MD), $\mathrm{PhD}$ in health sciences, $\mathrm{PhD}$ student of the 47 Doctoral School of Chemistry and Environmental Science of University of Pannonia 48 and research fellow at University of Pannonia, Veszprém, Hungary. His main field of 49 research is the impact of climate change on vector-borne diseases and the ecology of 50 arthropod vectors. 
The anthropogenic climate change, a gradual, long-term alteration of worldwide weather patterns caused by the increasing concentration of greenhouse gases (Jaha and Ekumah 2015; Zhong 2016; Aleixandre-Tudó et al. 2019), influences the complex society-biosphere-climate-economy-energy system (Akhtar et al. 2019), including diseases and their prevalence (Ofulla et al. 2016). Climate affects the human behaviors and activities, the structure of the settlements, the population of the host and reservoir mammals, the conditions of the potential tick habitats, and therefore, these mankindinduced effects change the pathogen transmission and, finally, the incidence of human tick-borne diseases (Lindgren 1998). Tick-borne diseases are the products of a complex chain of environmental factors (Epstein 1999). Changing climatic and other environmental factors affect the seasonality of the acquiring of tick-borne diseases via the alteration of the daily, the inter-annual and the long-term patterns in risk of infected tick bites (Lindgren and Jaenson 2006).

Ticks are small ectoparasite arachnid arthropods living by feeding on the blood of different homoiotherm and poikilotherm tetrapods. More than two dozen tick species occur in Hungary, but the sheep tick (Ixodes ricinus L. (Acari: Ixodidae)) is the most important in the aspect of environmental health. I. ricinus is the most common vector of Lyme borreliosis and also one of the most common ticks in many parts of Europe (Földvári and Farkas 2005; Rizzoli et al. 2014). The observed temporal and spatial expansion of the species in the past decades has been correlated to changes in climate of Europe (Lindgren and Jaenson 2006). It was concluded by several authors that climate change will lengthen the vegetation season and, consequently, the activity period of the different vector species (Hunter 2003; Rogers and Randolph 2006).

In the aspect of the adaptation strategies of medical and personal practices (i.e. the seasonal use of tick repellents, vaccines, the behavioral avoidance strategies) the distribution (i.e. seasonality, length and the peak) of the incidence of tick-borne diseases is more important than the total yearly incidence of them. In Hungary, the questing activity of I. ricinus nymphs and adults starts in March, reaches its maximum in April, shows its summer minimum in August and its second, less expressed peak in October (Széll et al. 2006; Egyed et al. 2012; Trájer and Földvári unpublished data). Despite of the bimodal distribution of tick activity and tick-borne encephalitis the distribution of Lyme borreliosis is unimodal (Zöldi et al. 2013; Trájer et al. 2014). Gray (2008) forewarns that the annual distribution of both I. ricinus activity and Lyme borreliosis may change significantly in the future due to climate change. It is therefore required to investigate the impact of climate change on their annual distribution (Ogden et al. 2005).

The development and activity of I. ricinus ticks, and the number of the questing ticks are related to the seasonal variation of temperature, in addition to that of other abiotic factors (e.g. humidity and photoperiodicity) that are hard to access or incorporate in a model (Randolph 2009; Jore et al. 2014; Cat et al. 2017). The relationship between temperature and both the interstadial development rates and the daily questing rate is non-linear (Randolph 2004; Trájer et al. 2014).

The aim of our study is to (1) build a framework with low number of inputs on modeling the annual distribution (seasonality) of Lyme borreliosis incidences based on week number and temperature, using human-tick interaction and I. ricinus tick activity as hidden modeling modules; to (2) calibrate this modeling framework for the period 1998-2008 for Hungary as a case study; and to (3) predict annual distribution of Lyme borreliosis incidence for a selected future period (2081-2100). Since absolute incidence 
depends on many factors that are not well studied (e.g. acorn production in the previous year (Ostfeld et al. 2006), rodent or mice population dynamics (Ostfeld et al. 2001; Schauber et al. 2005), and the overwintering rate of the different stages of ticks (Lindsay et al. 1995)), we aimed to model the distribution of the relative incidences (i.e. the sum of incidences per year is 100). Since absolute Lyme borreliosis incidences have nearly been doubled in the studied period in Hungary and the cause of this increase is not well understood (c.f. Trájer et al. 2013b; Zöldi et al. 2013), relativisation of incidence data is unavoidable in our study domain. Another benefit of the use of relative incidence values is the possibility of determining the notable dates of the distribution (season start, peak and end), and compare them between years. The model and its

111 predictions have weekly temporal resolution.

\section{MATERIALS AND METHODS}

\subsection{Data sources and data preprocessing}

\subsubsection{Weekly mean temperature (T)}

115 The daily mean temperature data of the reference period (1998-2008) were derived from 116 the E-OBS 7.0 database of the European Climate Assessment \& Dataset (Haylock et al 117 2008), while data of the future prediction period (2081-2100) were derived from the 118 MRI CGCM 2.3.2a model driven by the SRES A1B emission scenario (Yukimoto et al. 119 2006). Since the climatic and the geographical conditions are relatively homogenous in Hungary (Trájer et al. 2013b, Trájer et al. 2014) we could handle the country as a single unit in climatic terms. Pertinence of this simplification is proven by our previous findings on the homogeneity of LB seasonality within Hungary (Trájer et al. 2013a). Average values were calculated from the $0.25^{\circ}$ and $2.81^{\circ}$ grids (in case of reference and prediction periods, respectively) within the domain including almost the entire area of Hungary $\left(45.77^{\circ} \mathrm{N}-48.56^{\circ} \mathrm{N}, 16.15^{\circ} \mathrm{E}-22.85^{\circ} \mathrm{E}\right.$ in WGS- 84 coordinate system). Weekly mean temperature ( $T$ hereinafter) values were calculated by simple averaging of daily data.

\subsubsection{Human-tick interaction: holiday multiplier (HM)}

129 Socio-economic factors, such as the annual pattern of human activity and human-tick 130 interaction, may have a great influence on the annual Lyme borreliosis incidence (Šumilo et al. 2008). For a detailed review please refer to Pfäffle et al. (2013) and the studies cited within. According to our previous findings (Trájer et al 2014), human-tick interaction can be estimated by human outdoor activity patterns related to camping guest night data. Although camping data may cover a limited part of outdoor activities, it can serve as a proxy for approximation. Holiday multiplier ( $H M$ hereinafter) is a measure of human willingness to stay in nature (and therefore a measure of the potential human-tick interaction) in the summer holiday period, calculated as the ratio of the camping guest night data (observation) and the normal distribution of temperature dependent human outdoor activity (model). HM values of the $25-36^{\text {th }}$ weeks (Table 1 ) were interpolated from the results of Trájer et al. (2014) (original temporal resolution: two weeks). HMs were set to 1 in all the other weeks. 
143 The weekly incidence data of tick-borne encephalitis for the period 1998-2008 were 144 gained from the National Database of Epidemiological Surveillance System (OEK 145 2013), based on serological tests. Relative incidences were calculated from absolute 146 ones using technical years starting from the $11^{\text {th }}$ to the next year's $10^{\text {th }}$ week (total 147 incidences of all the technical years were $100 \%$ ). Weekly relative tick-borne 148 encephalitis incidences ( $T B E$ hereinafter) were averaged from the 11-years study period.

\subsubsection{Relative Lyme borreliosis incidence (LB)}

150 The weekly incidence data of Lyme borreliosis for the period 1998-2008 were gained 151 from the National Database of Epidemiological Surveillance System (OEK 2013). Since 152 the Hungarian mandatory system does not distinguish between the infection forms, we 153 defined the "case" as any type of early or late infection form of Lyme borreliosis. The 154 diagnosis in our database may be based on three main criteria: persons with typical 155 erythema migrans (EM) symptoms (most of the recorded cases), persons with late 156 clinical manifestations (arthritis and/or cardiac, neurological disorders, late phase EM), and persons with laboratory confirmed Lyme borreliosis due to different serological tests. Weekly relative Lyme borreliosis incidences ( $L B$ hereinafter) were calculated in similar way than TBEs were.

\subsubsection{Observed latency of Lyme infection}

To build a lag model used further in our research (please refer to Model II. A) we determined the lags between tick bites and the first manifestations sampled from the serological registration forms of the Hungarian National Reference Laboratory of Bacterial Zoonoses from the period of March 2012-August 2012. Less than the $10 \%$ of the serological registration forms contained both the data of the time of tick bites and the appearance of the EM symptoms $(n=26)$. Since most of the cases appeared 2-3 weeks after the tick bite it is plausible that these symptoms belonged to the early manifestation forms (e.g. EM, neuroborreliosis). A lag model, forming a lognormal-like shape, was built by approximating the observed lags between tick bites and onsets of the early manifestation form (Fig 1.). Model values were found to be negligible after the ninth week, therefore we used the first nine weeks later on.

\subsection{Modeling method}

\subsubsection{Model overview}

A two-phase model was built to estimate relative Lyme borreliosis incidence (LB) as an output from two input parameters that are week number (n) (started from January) and weekly average of the daily mean temperatures $(\mathrm{T})$. All the other (hidden) parameters, such as holiday multiplier (HM), tick activity (A), and biting activity (BA), are calculated by the model from these two inputs. The reason of building a two-phase model instead of a one-phase one was our aim to improve model reliability by a twophase calibration. The structure of the model and the sources of calibration are shown in

181 Fig 2. All the parameters of the model have weekly temporal resolution. For using the 182 model for real-time prediction one has to have the input $\mathrm{T}$ parameter for all the 52 
weeks before the studied week.

Script (function) of the model that can be run in R statistical software (R Core Team 2017) is provided (Github 2019). Although among the input $T$ values all the internal parameters and weights can be passed to the function, calibrated values are automatically used if they are not specified.

The first phase of the model (hereinafter Model $I$ ) is able to estimate tick activity and therefore the result of Model I may have relevance without the second phase (hereinafter Model II), i.e. for estimating tick density, tick-borne encephalitis incidence or the incidence of other tick-borne diseases. Model I is a composite of two models: the first one (hereinafter season 1) is responsible for the tick activity in the first half of the year, the second one (hereinafter season 2) is responsible for that of the second half of the year. The division of the year is not strict and is done automatically by the model based on $\mathrm{n}$ and $\mathrm{T}$ values. The calculation of season 1 is more complex than that of season 2, since season 1 takes the size of the active population - those ticks that have not yet bitten - into consideration. Tick activity is calculated by summarizing season 1 and season 2, since they may overlap each other (Eq. 1).

$$
A_{n}=A_{n}^{\text {season } 1}+A_{n}^{\text {season } 2}
$$

Since I. ricinus uses ambush strategy for host finding (Sonenshine 1991), the probability of the encounter and therefore that of the disease transmission, depends not only on tick activity but on human activity as well. Hence, infection is not directly linked to tick activity but to the human-tick interaction. Biting activity is calculated from tick activity and holiday multiplier (Eq. 2).

$$
B A_{n}=A_{n} * H M_{n}
$$

Model II is able to estimate relative Lyme borreliosis incidence from biting activity. If its input is available, Model II can be calibrated and used independently form Model I. Model II has three alternative versions (model A, model B, and model C) that differ from each other in terms of the calibration method. Model I and Model II is now going to be explained in detail. After that model calibration will be discussed.

\subsubsection{Model I, season 1}

Season 1 in Model I inevitably contains the spring activity of adult ticks, but the nymph activity seems to be dominant in causing Lyme infection from spring to late summer in Hungary (Egyed et al. 2012). Tick activity in season 1 is estimated according to that hard ticks take one blood meal per life stage (Randolph 2004) and therefore not all the nymphs (and adults) are unfed in a certain week. Hence, the value of population entirety (or active population, $\mathrm{P}$ ) has to be taken into account and continuously diminished week by week. P means the size of the active, unfed population (those ticks that ambush to bite) between 0 and 1 , where $P$ of the first week of the year is 1 (Eq. 3).

$$
P \in[0,1] ; P_{1}=1
$$

Tick activity is the function of the potential activity of the entire population (temperature dependent activity, TDA) and the size of the actual unfed tick population. The model calculates the active population of the current week iteratively from TDA and the active population of the previous week. The subtrahend $(\mathrm{S})$ is estimated from 
the tick activity and a weight parameter $(\delta)($ Eq. 4, Eq. 5).

$$
P_{n}=\left\{\begin{array}{c}
0, \text { if } P_{n-1}-S_{n-1} \leq 0 \\
P_{n-1}-S_{n-1}, \text { if } P_{n-1}-S_{n-1}>0
\end{array}\right.
$$

$$
S_{n}=T D A_{n} * \delta
$$

TDA means potential activity of the ticks that is dependent on temperature but independent on the population size. Therefore, TDA means the tick activity that can be measured if none of the specimens have been fed yet (if $\mathrm{P}=1$ ). TDA is calculated from the input temperature value and is based on a left-skewed lognormal distribution with axis $(\alpha)$ that separates the lognormal distribution in the left side and the constant 0 function in the right side. The lognormal distribution has a mean $(\mu)$ and standard deviation value $(\sigma)$ and is multiplied with a factor $(c)$ and then is increased with another factor (d). The input of the lognormal distribution is the difference of $\mathrm{T}$ and $\alpha$. TDA starts to have a non-zero value when the temperature is above $5{ }^{\circ} \mathrm{C}$ in two consecutive weeks (Eq. 6).

$$
T D A_{n}=\left\{\begin{array}{c}
0, \text { if } T_{n} \geq \alpha \vee T_{n} \leq 5 \vee\left(n \neq 1 \wedge T_{n-1} \leq 5\right) \\
c * \frac{1}{\left(\alpha-T_{n}\right) * \sqrt{2 \pi} * \sigma} * e^{-\frac{\left(\ln \left(\alpha-T_{n}\right)-\mu\right)^{2}}{2 \sigma^{2}}}+d, \text { else }
\end{array}\right.
$$

Tick activity (A) is calculated by the multiplication of TDA with the population entirety $240 \quad(\mathrm{P})$ as shown in Eq. 7.

$$
A_{n}=P_{n} * T D A_{n}
$$

242

Although TDA is usually a positive number (except in early spring and when the temperature is greater than the axis), A is going to constantly be 0 after the week when the P starts to be 0 (since all the specimens have been fed). Since the end of season 1 and the beginning of season 2 are not directly related to each other there may be a period in summer when both of them or none of them have positive value.

\subsubsection{Model I, season 2}

The model of season 2 is simpler than that of season 1 since no population is taken into account. It is thought that not the exhausted population but the cold temperature together with the change of photoperiod has impact on the finishing of season 2, and therefore there is no need to build a more complex model. Hence, TDA and A are synonyms of each other in case of season 2 and $\mathrm{P}$ is set to be always 1 . Tick activity is calculated in a similar way to the equation shown in Eq. 6, except the conditions of the two branches. In addition to that the temperature must be lower than the axis and greater than $5{ }^{\circ} \mathrm{C}$, A has a positive value from a certain week. This positive period begins when the temperature drops below $20^{\circ} \mathrm{C}$ (after the warmest week of the year and after the 28 . week) (Eq. 8). Since in case of real-time prediction the start of the period cannot be calculated from the temperature values of the studied year, one can estimate maximum temperature from the previous 52 weeks. 


\subsubsection{Model II}

(Eq. 8)
Model II has the capability to estimate the LB based on the sum of the product of BA and the weight factor $(\omega)$ of some of the previous weeks. The three versions of Model II use different number of weeks. While model A uses exactly 9 weeks, model B and C are able to use much more data and the exact number of the important weeks is gained during the model calibration. The difference is detailed in the next chapter. To be consistent in mathematical terms $\omega=0$ weights are used when a model cannot calculate with that certain week. Hence, all the three models have the similar equation (Eq. 9).

$$
L B_{n}=\sum_{i=1 . .52}\left(B A_{n-53+i} * \omega_{i}\right)
$$

\subsection{Model calibration}

The model was calibrated with input data averaged in the 11 years long period of 19982008. Therefore, future prediction needs input data from a similarly long period. In case of prediction with input data available from a shorter period (especially in case of realtime prediction) the model has to be recalibrated.

The advantage of the two-phase model is that it has the possibility to calibrate the model in two independent phases. In addition to the model inputs and the expected output, we estimated BA that is a hidden parameter of the model. BA was approximated by TBE data as proxy using a one-week shift (Eq. 10), since, in contrast to TBE, the distribution of $I$. ricinus biting activity in weekly resolution is not known. Prodromal symptoms of TBE appears about one week after tick bite and in general persist to the second week before the neurological symptoms appear in the third week. Thus, shifting TBE by one week may provide a well-established estimation of BA. In contrast to TBE, using LB for calibration of BA would be less straightforward due to the complex and multiphase nature of the manifestations of Lyme borreliosis infection.

$$
B A_{n}=T B E_{n+1}
$$

In case of Model II the so called model A was calibrated by using the observed latency according to the serological application forms (in detail see Chapter 2.1.5). For calibrating Model I, and Model II versions called B and C Solver add-in of Microsoft Excel 2010 was used. Solver can find optimal solution (reduce the error of the model) by adjusting parameters, subject to constraints. We used Generalized Reduced Gradient nonlinear optimization from the several alternative optimization methods that Solver provides. In case of Model I Solver calibrated 11 parameters simultaneously that are the weight parameter $(\delta)$, and axis $(\alpha)$, mean $(\mu)$, standard deviation $(\sigma)$, multiplier $(c)$ and difference (d) in case of season 1 and season 2 . The set objective of the calibration was to reduce the sum of squared errors of prediction (SSE) of tick activity (A). It should be noted that calibration with such a high number of parameters has difficulties in case of any automatic calibration processes. Therefore, iteratively more and more parameters had been included in the calibration before the final calibration was done to ensure that 
Solver finds the best solution not a local extreme value of SSE.

In case of Model II the set objective was to reduce the sum of squared errors of

\section{RESULTS}

\subsection{Model calibration results}

315 Weight parameter $(\delta)$ of Model I was calibrated to be 0.0078 , while the other calibrated parameters can be found in Table 2. Equations of the lognormal distribution of season 1 and season 2 (Eq. 6, Eq. 8) are now updated with the calibrated parameters (Eq. 11, Eq. 12).

(Eq. 12)

Calibration results of Model II can be seen in Table 3. The zero values that were not calibrated but fixed are marked. Sums of the weights should be near 1. Sums of squared errors of prediction (SSE) of relative Lyme borreliosis incidence can be found in Table 3 for making a comparison between the three models. Note that the set objective of Solver was to minimize SSE in case of model B and model C. Model A seems to be worse than model $\mathrm{B}$ and $\mathrm{C}$ in one order of magnitude. Model $\mathrm{C}$ is found to be the best of the three model version, although model B (with 52 adjustable parameters instead of 20) had the ability to take precedence over model C. This result shows that Solver found local extreme during calibration of model $\mathrm{B}$. The authors suggest using model $\mathrm{C}$ instead of the other ones. The provided $\mathrm{R}$ function (Github 2019) uses automatically model $\mathrm{C}$ and the calibrated parameters and weights if they are not passed to the function.

\subsection{Prediction of relative biting activity}

336 The modeled distribution of relative tick biting activity (BA; Fig 3 ) in the reference 337 period is bimodal with a major peak in the second part of May and a clear but minor 
peak in late September. According to the similar run of the tick activity curves of the model and the calibration data, the model was calibrated well. The prediction to the period of 2081-2100 shows that the two parts of the biting activity curve will be separated more markedly. This finding is consistent with the expectations. Maximum of the activity is predicted to be shifted 8 weeks earlier, while the tick season may start 6-7 weeks earlier than in the reference period. Significant prolongation of the fall season is not predicted, therefore the whole tick season seems to become 6-7 weeks longer in the future. However, if summer diapause is taken into account, the length of the period when ticks are effectively active will not be changed. The fall local maximum may shift from the $40^{\text {th }}$ to the $33^{\text {rd }}-34^{\text {th }}$ weeks and become more pronounced according to the prediction. In terms of its scale, the fall maximum may almost reach the spring one causing bimodality of relative tick activity become more explicit.

\subsection{Prediction of relative lyme borreliosis incidence}

The three predictions to the reference period (Fig 4, black lines) prove the findings of the calibration about model errors. Model B and model $\mathrm{C}$, those that were trained algorithmically, fit better to the observed Lyme borreliosis curve than model A does. While prediction of model B and that of model C are largely similar to each other, advantage of model $\mathrm{C}$ over the other one can be seen in the weeks 24-29. Unimodal annual distribution of the Lyme borreliosis incidences are obviously shown by all the three predictions.

Future predictions (Fig 4, gray lines) demonstrate the bimodalization of the annual incidence distribution by the end of the $21^{\text {st }}$ century. The bimodal distribution shows similar characteristics to that of the predicted future relative tick biting activity, especially in case of model A. All the three models predict the elongation of the total Lyme borreliosis season by about 8 weeks. However, the effective length of the season seems to be shortened in the future by some weeks, due to the narrowing of the main curve. Although predictions to the future and the reference period are somewhat similar to each other after the $38^{\text {th }}$ week, they are largely different before. From $26^{\text {th }}$ to $34^{\text {th }}$ weeks LBs are close to zero, while the period of the weeks no. 13-24 may be highly endangered by Lyme borreliosis. The maximum relative incidence will shift from the currently observed $27^{\text {th }}$ week to the $18^{\text {th }}-19^{\text {th }}$ weeks, according to the predictions. The three models agree that fall local maximum will occur in the $36^{\text {th }}$ week but the LB is predicted to be one and a half time higher by model A than by model B and C. With reference to the previously written calibration results, we may conclude that model A is performing poorly for the future period too and overestimates maxima of LB.

\section{4. DISCUSSION}

\subsection{Model advantages and improvements}

Although a lot of model parameters had been calibrated by Solver simultaneously in case of Model I. and Model II., calibration found optimal solution in both cases and the calibrated model predicted the annual distribution of Lyme borreliosis incidences with low error values. Hence, the complexity of the model is thought to be not too high but not too low either, since the model can estimate the expected output parameter (i.e. the relative Lyme borreliosis incidence of a certain week) well. An important advantage of our model is that it needs temperature data only as input parameter in addition to the 
week numbers (c.f. Wu et al.'s (2010) model on I. scapularis population). Observed or 383 predicted daily/weekly temperatures are easily available data with high horizontal and 384 temporal resolution for a great part of the world and for a wide range of past and future time periods. Therefore, our modeling framework is thought to be a not input-intensive, easy-to-use estimator of Lyme borreliosis infection.

Our framework contains several innovations in modeling the annual distribution of Lyme borreliosis incidence: (1) the model is calibrated in two phases, where the first phase describes the biting activity of ticks; (2) human-tick interaction is taken into account and estimated using camping guest night data (c.f. Šumilo et al. 2008; Pfäffle et al. 2013); (3) the spring and fall seasons are modeled separately due to their different activity patterns and their different dependence on climate; (4) a simple and straightforward population dynamics module is implemented in Model I, season 1. Although it is clear that activity patterns of the two modeled seasons differ from each other in the region of our study, it is not yet known if they are related only with the different seasonal activity of the nymph and adult ticks. Although findings of Hornok and Farkas (2009) and Egyed et al. (2012) for Hungary, and also Randolph et al. (2002), Takken et al. (2016) and Cayol et al. (2017) for other regions cannot strengthen our supposition, there is evidence on the dominance of nymphs in spring and that of the adults in fall (Trájer and Földvári unpublished data). Since adults are active in spring as well (Randolph et al. 2002; Hornok and Farkas 2009; Egyed et al. 2012), Model I, season 1 was built to deal with nymphs and adults jointly. However, the higher infection rate of the nymphs (Olsén et al. 1995) and their more efficient Borrelia transmission due to their less perceptibility support that the population dynamics module based on the questing behavior of nymphs was implemented in Season 1. This module can describe the abundance-meditated probability of questing, similarly to the model of Dobson et al. (2011).

Even if Model I cannot substitute for tick flagging, the indirect biting activity data derived from tick-borne encephalitis used in the our study may be more suitable for analyzing temperature-related seasonal tick activity patterns than field surveys due to their high temporal resolution, accessibility, and higher sample size. Although from an unconventional aspect (i.e. backward conclusion from incidence data), our model highlights the significance of the nosocomial surveillance systems. Determination of the exact time of tick bite based on the notification system of Lyme infection is biased, since (1) erythema migrans begins after a delay of 3 to 30 days after tick bite (in average 2 weeks latency); (2) the time of the human-tick encounter that enable tick bite is often not known exactly; (3) the reported Lyme borreliosis cases contain the mixture of different stages that have different latencies; (4) the notification probability of the different stages is different. Our modeling framework provides a simple workaround that eliminates these uncertainties. Biting activity is calculated from temperature, week number and the probability of human-tick interaction (i.e. holiday multiplier), and is calibrated by the much more consistent, reliable and predictable tick-borne encephalitis (Gray et al. 2009) instead of Lyme borreliosis data (c.f. the suggestion of Bózsik (2004) on the use of tick-borne encephalitis series to predict Lyme borreliosis series). The modeling framework needs another calibration method in countries without tick-borne encephalitis incidence. Three different latency models are then used to convert biting activity series to LB series, among them two models are calibrated automatically. These enhancements ensure that biting activity is highly independent from Lyme borreliosis incidences and is calibrated with low uncertainty. The predicted annual distribution of biting activity in the reference period is highly similar to the results of field studies (Széll et al. 2006; Egyed et al. 2012; Trájer and Földvári unpublished data). 
433 According to our results, start of the tick biting activity and Lyme borreliosis season, 434 length of the season, and other seasonal characteristics of the annual distribution are 435 highly sensitive to temperature, and hence, to climate change. Our findings underpin 436 those of previous researches on the impact of climate on the vector (e.g. Lindgren et al. 2000; Gray et al. 2009; Jaenson and Lindgren 2011; Trájer et al. 2013a; Li et al. 2016), the disease (Jaenson and Lindgren 2011; Li et al. 2016), and the bacteria Borrelia burgdorferi (Estrada-Peña et al. 2011). Hornok and Farkas (2009) found, however, that the spring timing of the peak activity of I. ricinus was unaffected by the warm weather of 2007 in the Hungary. It has been observed that the increasing length of the vegetation period elongated the Lyme borreliosis season in the 2000's in Hungary (Trájer et al. $2013 \mathrm{~b}$ ), which trend is predicted by our model to continue in the future.

Although our model might be biased and its future prediction might be inaccurate, the significant change of the annual distribution is clear and inevitable. Such change of the climatic patterns may also cause future shift in the geographical distribution of I. ricinus (Lindgren et al. 2000; Jore et al. 2014; Sormunen et al. 2016; Li et al. 2016) and its close relative, the blacklegged tick, Ixodes scapularis (Estrada-Peña 2002; Brownstein et al. 2003; Ogden et al. 2008), which has already been observed in the last decades (Daniel 1993; Daniel and Dusbabek 1994; Lindgren et al. 2000). Please refer to Estrada-Peña (2008) for a critical review of these findings. It is an open question how climate change will trigger the northward move of Mediterranean tick species, however, the European range and distribution of the population of such Mediterranean tick species like of Dermacentor reticulatus shows a stable increasing trend in Europe and the Carpathian Basin (Földvári et al. 2016).

Since spring is predicted to be warmer, and the summer will be drier and hotter in Hungary according to the climate models (Pieczka et al. 2018), the forecasted bimodal distribution of tick biting activity and Lyme borreliosis incidence is consistent with our expectations. Our findings underpinned that the apparent contradiction between the unimodal distribution of Lyme borreliosis and bimodal distribution of tickborne encephalitis might be the result of the different incubation periods of the organic manifestations rather than the consequence of the different seasonal infection rate or the difference of the vector species.

Extreme events (e.g. heat) might become more intensive and frequent in the future (Bai et al. 2016), which trend is attributed to global climate change by researchers (Göndöcs et al. 2018) and stakeholders (Malatinszky et al. 2013) as well. Their increasing frequency creates an uncertain basis for environmental predictions (Şen 2018). Therefore, understanding and, if necessary, reducing their impact is an important topic of climate change studies (Birkmann and Welle 2015). Our framework can predict the tick biting activity in the periods of extreme heat more reliably than the models that are prone to overestimate it (e.g. Cat et al. 2017). Previous findings on the accelerated phenology of ticks in the warming future climate (Süss et al. 2008; Levi et al. 2015; Li et al. 2016) is strengthen by our results.

\subsection{Usability of the model and limitations of the result interpretation}

Model I is suggested to be used to calculate tick biting activity (and indirectly tick activity, tick density, and more indirectly relative incidence of tick-borne encephalitis), while the authors recommend using Model II to estimate relative Lyme borreliosis incidence (and indirectly absolute Lyme borreliosis incidence). The provided $\mathrm{R}$ script 
479 (Github 2019) is thought to enhance the usability of our model since it need only 480 weekly temperature series and returns the result of both modeling phases (relative biting 481 activity, relative Lyme borreliosis incidence). It provides an effective tool for those who 482 need quick prediction (by using default, calibrated parameters) and for those, as well, 483 who have recalibrated the model and could pass the recalculated parameters to the 484 function.

Despite that some other environmental factors (e.g. precipitation, humidity) might have role on determining the distribution of Lyme borreliosis incidence (Randolph 2009; Jore et al. 2014; Cat et al. 2017), we presented a highly inputextensive, simple modeling framework that uses, among the calibration data, only temperature and week number as input parameters. Since humidity is highly affected by vegetation, nearness of water bodies, and urbanization level, fine resolution humidity data that are free from these biases is hardly accessible. Since both the present (i.e. reference period) and future predictions of our model meet our previous expectations, we conclude that the observed summer decrease of the Lyme borreliosis incidence is not necessarily or solely the consequence of the low summer precipitation or reduced humidity as many author claimed (e.g. Schauber et al. 2005; Ostfeld et al. 2006). Tick population dynamics, which was applied in Model I, season 1, can be an alternative explanation of the observed patterns of the summer distribution, at least in Hungary. Although the decreasing numbers of questing ticks might be the consequence of several factors, such as increased mortality due to changing meteorological conditions, our model confirmed that one and major determinant of the decrease is the loss of hungry tick population due to their previous bite.

Climate is not the only one important environmental factor which can have impact on tick-borne diseases in Hungary. It was also found that inexperienced farmers who have a lower rate of preventive actions are likely to experience greater exposure to tick bites in Hungary ( $\mathrm{Li}$ et al. 2018). It cannot be excluded that the reduced use of pesticides in tick control in the urban environment also influenced the abundance of the urban tick populations in the last decades in Hungary.

Since the main objectives of model building includes simplification of reality by making assumptions and generalizations, its tradeoffs are amplified when reduction of model complexity and the number of input parameters is aimed. Therefore, we should list the weaknesses and limitations of the model:

1) camping guest night data can serve only as a proxy of human outdoor activities: its annual distribution may differ from that of all the outdoor activities and cannot cover people of occupational risk groups, e.g. foresters;

2) complex ecology of I. ricinus can approximated but not fully described if no other environmental factors than temperature are considered. Although temperature is correlated to photoperiodicity, relative humidity and saturation deficit, it cannot replace the other abiotic factors. For simplicity, we must accept the improper assumption that temperature can describe the tick's annual distribution;

3) the tick-borne encephalitis data used for calibration is limited to part of the geographic range of I. ricinus. Hence, other data source is required for calibration in such territories. Surveillance data is prone to several type of biases, including geographical bias, reporting bias and inaccurate diagnosis etc.;

4) both Lyme borreliosis and tick-borne encephalitis data may suffer from the difficulties in case definition criteria, latency of infection, great variability of human response and that of the pathogenicity of the agents; 
5) instead of a reasonable but more complex birth-rate distribution, all

\section{CONCLUSION}

554 The presented framework with low number of inputs on modeling the seasonality of 555 Lyme borreliosis incidences enables predicting the annual distribution of Ixodes ricinus tick's biting activity and Lyme borreliosis in two cascading phases, using only the easily accessible weekly temperature data and week numbers as input parameters. Based on the implemented innovations incorporated in our model (i.e. two phases; population dynamics model of the spring season; tick-borne encephalitis series as a proxy for tick biting activity during the calibration; human-tick interaction approximated by camping data), it provides a simple workaround for several known issues of modeling Lyme seasonality, including the hardly available data on tick activity. According to the prediction to the future period of 2081-2100 based on MRI CGCM regional climate model and A1B emission scenario, climate change may significantly alter both the annual distribution of I. ricinus activity and that of the Lyme borreliosis incidences. While the currently unimodal annual distribution of Lyme borreliosis is predicted to become bimodal with a long summer pause and a spring maximum shifted 8 weeks earlier, the bimodality of I. ricinus activity may also become more expressed.

570 The authors would like to express their gratitude to Gábor Földvári (Department of Parasitology 571 and Zoology, University of Veterinary Medicine Budapest, Hungary) for his comments on an 
early version of this paper. The project was supported by the GINOP-2.3.2-15-2016-00019 grant.

\section{REFERENCES}

Akhtar MK, Simonovic SP, Wibe J, MacGee J (2019): Future realities of climate change impacts: an integrated assessment study of Canada. Int J Global Warm 17(1): 59-88. http://dx.doi.org/10.1504/JJGW.2019.096761

Aleixandre-Tudó JL, Bolaños-Pizarro M, Aleixandre JL, Aleixandre-Benavent R (2019): Current trends in scientific research on global warming: a bibliometric analysis. Int J Global Warm 17(2): 142-169. http://dx.doi.org/10.1504/IJGW.2019.097858

Bai H, Dong X, Zeng S, Chen J (2016): Assessing the potential impact of future precipitation trends on urban drainage systems under multiple climate change scenarios. Int J Global Warm 10(4): 437-453. http://dx.doi.org/10.1504/IJGW.2016.079776

Birkmann J, Welle T (2015): Assessing the risk of loss and damage: exposure, vulnerability and risk to climate-related hazards for different country classifications. Int J Global Warm 8(2): 191-212. http://dx.doi.org/10.1504/IJGW.2015.071963

Bózsik BP (2004): Prevalence of Lyme borreliosis. Lancet 363: 901. http://dx.doi.org/10.1016/S0140-6736(04)15756-5

Brownstein JS, Holford TR, Fish D (2003): A Climate-Based Model Predicts the Spatial Distribution of the Lyme Disease Vector Ixodes scapularis in the United States. Environ Health Perspect 111(9): 1152-1157. http://dx.doi.org/10.1289/ehp.6052

Burtis JC, Sullivan P, Levi T, Oggenfuss K, Fahey TJ, Ostfeld RS (2016): The impact of temperature and precipitation on blacklegged tick activity and Lyme disease incidence in endemic and emerging regions. Parasit Vectors 9(1): 606. http://dx.doi.org/10.1186/s13071-016-1894-6

Cat J, Beugnet F, Hoch T, Jongejan F, Prangé A, Chalvet-Monfray K (2017): Influence of the spatial heterogeneity in tick abundance in the modeling of the seasonal activity of Ixodes ricinus nymphs in Western Europe. Exp Appl Acarol 71(2): 115-130. http://dx.doi.org/10.1007/s10493-016-0099-1

Cayol C, Koskela E, Mappes T, Siukkola A, Kallio ER (2017): Temporal dynamics of the tick Ixodes ricinus in northern Europe: epidemiological implications. Parasit Vectors 10(1): 166. http://dx.doi.org/10.1186/s13071-017-2112-x

Daniel M, Dusbabek F (1994): Micrometeorological and microhabitat factors affecting maintenance and dissemination of tick-borne diseases in the environment. In: Sonenshine DE, Mather TN (eds.): Ecological dynamics of tick-borne zoonoses. New York, NY, USA: Oxford University Press.

Daniel, M. (1993). Influence of the microclimate on the vertical distribution of the tick Ixodes ricinus (L.) in central Europe. Acarologia 34(2): 105-113.

Dobson ADM, Finnie TJR, Randolph SE (2011): A modified matrix model to describe the seasonal population ecology of the European tick Ixodes ricinus. J Appl Ecol 48(4): 1017-1028. http://dx.doi.org/10.1111/j.1365-2664.2011.02003.x

Egyed L, Élő P, Sréter-Lancz Z, Széll Z, Balogh Z, Sréter T (2012): Seasonal activity and tick-borne pathogen infection rates of Ixodes ricinus ticks in Hungary. Ticks Tick Borne Dis 3: 90-94. http://dx.doi.org/10.1016/j.ttbdis.2012.01.002

Epstein PR (1999): Climate and health. Science 285(5426): 347-348. http://dx.doi.org/10.1126/science.285.5426.347 
Estrada-Peña A (2002): Increasing habitat suitability in the United States for the tick that transmits Lyme disease: a remote sensing approach. Environ Health Perspect 110: 635-640. http://dx.doi.org/10.1289/ehp.02110635

Estrada-Peña A (2008): Climate, niche, ticks, and models: what they are and how we should interpret them. Parasitol Res 103(Suppl 1): 87-95. http://dx.doi.org/10.1007/s00436-008-1056-7

Estrada-Peña A, Ortega C, Sánchez N, DeSimone L, Sudre B, Suk JE, Semenza JC (2011): Correlation of Borrelia burgdorferi Sensu Lato Prevalence in Questing Ixodes ricinus Ticks with Specific Abiotic Traits in the Western Palearctic. Appl Environ Microb 77(11): 3838-3845. http://dx.doi.org/10.1128/AEM.00067-11

Földvári G, Farkas R (2005): Ixodid tick species attaching to dogs in Hungary. Vet Parasitol 129: 125-131.

Földvári G, Siroky P, Majoros G, Szekeres S, Sprong H (2016): Dermacentor reticulatus: a vector on the rise. Parasite Vector 9: 314. https://doi.org/10.1186/s13071-016-1599-x

Github (2019): R script of the model. URL: github.com/bfakos/lyme_model/blob/master/Supplementary_material_S1.r

Göndöcs J, Breuer H, Pongrácz R, Bartholy J (2018): Projected changes in heat wave characteristics in the Carpathian Basin comparing different definitions. Int $\mathrm{J}$ Global Warm 16(2): 119-135. http://dx.doi.org/10.1504/IJGW.2018.094552

Gray JS (2008): Ixodes ricinus seasonal activity: Implications of global warming indicated by revisiting tick and weather data. Int J Med Microbiol 298(S1): 1924. http://dx.doi.org/10.1016/j.ijmm.2007.09.005

Haylock MR, Hofstra N, Klein Tank AMG, Klok EJ, Jones PD, New M (2008): A European daily high resolution gridded data set of surface temperature and precipitation for 1950-2006. J Geophys Res-Atmos 113(D20). http://dx.doi.org/10.1029/2008JD010201

Hornok S, Farkas R (2009): Influence of biotope on the distribution and peak activity of questing ixodid ticks in Hungary. Med Vet Entomol 23: 41-46. http://dx.doi.org/10.1111/j.1365-2915.2008.00768.x

Hunter PR (2003): Climate change and waterborne and vector borne disease. J Appl Microbiol 94(S1): 37-46. http://dx.doi.org/10.1046/j.1365-2672.94.s1.5.x

Jaenson TGT, Lindgren E (2011): The range of Ixodes ricinus and the risk of contracting Lyme borreliosis will increase northwards when the vegetation period becomes longer. Ticks Tick-borne Dis 2(1): 44-49. http://dx.doi.org/10.1016/j.ttbdis.2010.10.006

Jaha IR, Ekumah EK (2015): Climate change, fish catch and premix fuel supply to fishermen for sustainable livelihoods of coastal people in the central region of Ghana. Int J Global Warm 8(4): 453-462. http://dx.doi.org/10.1504/IJGW.2015.073050

Jore S, Vanwambeke SO, Viljugrein H, Isaksen K, Kristoffersen AB, Woldehiwet Z, Johansen B, Brun E, Brun-Hansen H, Westermann S, Larsen IL, Ytrehus B, Hofshagen M (2014): Climate and environmental change drives Ixodes ricinus geographical expansion at the northern range margin. Parasit Vectors 7(1): 11. http://dx.doi.org/10.1186/1756-3305-7-11

Levi T, Keesing F, Oggenfuss K, Ostfeld RS (2015): Accelerated phenology of blacklegged ticks under climate warming. Phil Trans R Soc B 370(1665): 20130556. http://dx.doi.org/10.1098/rstb.2013.0556

Li S, Gilbert L, Harrison PA, Rounsevell MDA (2016): Modelling the seasonality of Lyme disease risk and the potential impacts of a warming climate within the 
686

687

688

689

690

691

692

693

694

695

696

697

698

699

700

701

702

703

704

705

706

707

708

709

710

711

712

713

714

715

716

717

718

heterogeneous landscapes of Scotland. J R Soc Interface 13(116): 20160140. http://dx.doi.org/10.1098/rsif.2016.0140

Li S, Juhász-Horváth L, Trájer A, Pintér L, Rounsevell MDA, Harrison PA (2018): Lifestyle, habitat and farmers' risk of exposure to tick bites in an endemic area of tick-borne diseases in Hungary. Zoonoses Public Health 65(1): e248-e253. http://dx.doi.org/10.1111/zph.12413

Lindgren E (1998): Climate change, tick-borne encephalitis and vaccination needs in Sweden - a prediction model. Ecol Model 110(1): 55-63.

Lindgren E, Talleklint L, Polfeldt T (2000): Impact of climatic change on the northern latitude limit and population density of the disease-transmitting European tick Ixodes ricinus. Environ Health Perspect 108: 119-123. http://dx.doi.org/10.1289/ehp.00108119

Lindgren E, Jaenson TG (2006): Lyme borreliosis in Europe: influences of climate and climate change. epidemiology, ecology and adaptation measures. Copenhagen, Denmark: World Health Organization.

Lindsay LR, Barker IK, Surgeoner GA, McEwen SA, Gillespie TJ, Robinson JT (1995): Survival and development of Ixodes scapularis (Acari: Ixodidae) under various climatic conditions in Ontario, Canada. J Med Entomol 32: 143-152. http://dx.doi.org/10.1093/jmedent/32.2.143

Malatinszky Á, Ádám Sz, Saláta-Falusi S, Saláta D, Penksza K (2013): Planning management adapted to climate change effects in terrestrial wetlands and grasslands. Int J Global Warm 5(3): 311-325. http://dx.doi.org/10.1504/IJGW.2013.055365

OEK (2013): Országos Epidemiológiai Központ. [National Center for Epidemiology]. URL: www.oek.hu [Last accessed: 03/01/2013].

Ofulla AVO, Gichere SK, Olado GO, Abuom PO, Anyona DN, Othero DM, Matano AS, Gelder FB, Dida GO, Ouma C, Owuor PO, Amayi JB, Kanangire CK (2016): Effects of regional climate variability on the prevalence of diseases and their economic impacts on households in the Lake Victoria basin of Western Kenya. Int J Global Warm 10(1-3): 332-353. http://dx.doi.org/10.1504/IJGW.2016.077899

Ogden NH, Bigras-Poulin M, O'Callaghan CJ, Barker IK, Lindsay LR, Maarouf A, Smoyer- Tomic KE, Waltner-Toews D, Charron D (2005): A dynamic population model to investigate effects of climate on geographic range and seasonality of the tick Ixodes scapularis. Int J Parasitol 35: 375-389. http://dx.doi.org/10.1016/j.ijpara.2004.12.013

Ogden NH, St-Onge L, Barker IK, Brazeau S, Bigras-Poulin M, Charron DF, Francis CM, Heagy A, Lindsay LR, Maarouf A, Michel P, Milord F, O'Callaghan CJ, Trudel L, Thompson RA (2008): Risk maps for range expansion of the Lyme disease vector, Ixodes scapularis, in Canada now and with climate change. Int J Health Geogr 7: 24. http://dx.doi.org/10.1186/1476-072X-7-24

Olsén B, Jaenson TG, Bergström S (1995): Prevalence of Borrelia burgdorferi sensu lato-infected ticks on migrating birds. Appl Environ Microbiol 61(8): 30823087.

Ostfeld RS, Canham CD, Oggenfuss K, Winchcombe RJ, Keesing F (2006): Climate, deer, rodents, and acorns as determinants of variation in Lyme-disease risk. PLoS Biol 4(6): e145. http://dx.doi.org/10.1371/journal.pbio.0040145

Ostfeld RS, Schauber EM, Canham CD, Keesing F, Jones CG, Wolff JO (2001): Effects of acorn production and mouse abundance on abundance and Borrelia 
burgdorferi infection prevalence of nymphal Ixodes scapularis ticks. Vector Borne Zoonotic Dis 1: 55-63. diseases. Int J Parasitol 43(12-13): 1059-1077.

Pieczka I, Pongrácz R, Bartholy J, Szabóné André K (2018): Future temperature projections for Hungary based on RegCM4.3 simulations using new Representative Concentration Pathways scenarios. Int J Global Warm 15(3): 277-292. http://dx.doi.org/10.1504/IJGW.2018.093121

R Core Team (2017): R: A language and environment for statistical computing. $\mathrm{R}$ Foundation for Statistical Computing, Vienna, Austria. URL: www.Rproject.org.

Randolph SE (2009): Epidemiological consequences of the ecological physiology of ticks. Adv Insect Physiol 37: 297-339.

Randolph SE (2004): Tick ecology: processes and patterns behind the epidemiological risk posed by ixodid ticks as vectors. Parasitology 129(Suppl): S37-S65. http://dx.doi.org/10.1017/S0031182004004925

Randolph SE, Green RM, Hoodless AN, Peacey MF (2002): An empirical quantitative framework for the seasonal population dynamics of the tick Ixodes ricinus. Int J Parasitol 32: 979-989. http://dx.doi.org/10.1016/S0020-7519(02)00030-9

Rizzoli A, Silaghi C, Obiegala A, Rudolf I, Hubálek Z, Földvári G, Plantard O, Vayssier-Taussat M, Bonnet S, Spitalska E, Kazimirová M (2014): Ixodes ricinus and its transmitted pathogens in urban and peri-urban areas in Europe: new hazards and relevance for public health. Front Public Heal 2: 251. http://dx.doi.org/10.3389/fpubh.2014.00251

Rogers DJ, Randolph SE (2006): Climate change and vector-borne diseases. Adv Parasitol 62: 345-381. http://dx.doi.org/10.1016/S0065-308X(05)62010-6

Schauber EM, Ostfeld RS, Evans AS Jr (2005): What is the best predictor of annual Lyme disease incidence: weather, mice, or acorns? Ecol Appl 15(2): 575-586. http://dx.doi.org/10.1890/03-5370

Şen Z (2018): Noah and Joseph effects: floods and droughts under global warming. Int J Global Warm 16(3): 347-364. http://dx.doi.org/10.1504/IJGW.2018.095390

Shope R (1991): Global climate change and infectious diseases. Environ Health Perspect 96: 171-174. http://dx.doi.org/10.1289/ehp.9196171

Sonenshine DE (1991): Biology of Ticks, vol. 1. New York, NY, USA: Oxford University Press.

Sormunen JJ, Klemola T, Vesterinen EJ, Vuorinen I, Hytönen J, Hänninen J, Ruohomäki K, Sääksjärvi IE, Tonteri E, Penttinen R (2016): Assessing the abundance, seasonal questing activity, and Borrelia and tick-borne encephalitis virus (TBEV) prevalence of Ixodes ricinus ticks in a Lyme borreliosis endemic area in Southwest Finland. Ticks and Tick-borne Diseases 7(1): 208-215. http://dx.doi.org/10.1016/j.ttbdis.2015.10.011

Széll Z, Sréter-Lancz Z, Márialigeti K, Sréter T (2006): Temporal distribution of Ixodes ricinus, Dermacentor reticulatus and Haemaphysalis concinna in Hungary. Vet Parasitol 141(3-4): 377-379. http://dx.doi.org/10.1016/j.vetpar.2006.06.008

Šumilo D, Bormane A, Asokliene L, Vasilenko V, Golovljova I, Avsic-Zupanc T, Hubalek Z, Randolph SE (2008): Socio-economic factors in the differential upsurge of tick-borne encephalitis in central and Eastern Europe. Rev Med Virol 18(2): 81-95. 
Süss J, Klaus C, Gerstengarbe FW, Werner PC (2008): What makes ticks tick? Climate change, ticks, and tick-borne diseases. J Travel Med 15(1): 39-45. http://dx.doi.org/10.1111/j.1708-8305.2007.00176.x

\section{TABLES}

Table 1 . Weekly values of holiday multiplier (HM) other than 1

\begin{tabular}{|l|l|}
\hline number of week & holiday multiplier (HM) \\
\hline 25 & 1.29 \\
\hline 26 & 1.59 \\
\hline 27 & 1.91 \\
\hline 28 & 2.24 \\
\hline 29 & 2.36 \\
\hline 30 & 2.49 \\
\hline 31 & 2.74 \\
\hline 32 & 2.99 \\
\hline 33 & 2.61 \\
\hline 34 & 2.22 \\
\hline 35 & 1.65 \\
\hline 36 & 1.08 \\
\hline
\end{tabular}
Infections Across Space and Time in The Netherlands. Vector Borne Zoonotic Dis 17(2): 99-107. http://dx.doi.org/10.1089/vbz.2015.1933

Trájer A, Bobvos J, Krisztalovics K, Páldy A (2013a): Regional differences between ambient temperature and incidence of Lyme disease in Hungary. Időjárás Quarterly Journal of the Hungarian Meteorological Service 117(2): 175-186.

Trájer AJ, Bobvos J, Páldy A, Krisztalovics K (2013b): Association between incidence of Lyme disease and spring-early summer season temperature changes in Hungary - 1998-2008. Ann Agric Environ Med 20(2): 245-251.

Trájer A, Bede-Fazekas Á, Hufnagel L, Bobvos J, Páldy A (2014): The paradox of the binomial Ixodes ricinus activity and the observed unimodal Lyme borreliosis season in Hungary. Int J Environ Health Res 24(3): 226-245.

Wu X, Duvvuri VRSK, Wu J (2010): Modeling dynamical temperature influence on tick Ixodes scapularis population. In: Swayne DA, Yang W, Voinov AA, Rizzoli A, Filatova T (eds.): International Congress on Environmental Modelling and Software. Modelling for Environment's Sake, Fifth Biennial Meeting. Ottawa, Canada: International Environmental Modelling and Software Society.

Yukimoto S, Noda A, Uchiyama T, Kusunoki S, Kitoh A (2006): Climate changes of the twentieth through twenty-first centuries simulated by the MRI-CGCM2.3. Pap Meteor Geophys 56: 9-24. http://dx.doi.org/10.2467/mripapers.56.9

Zhong CX (2016): Causes of global climate change. Int J Global Warm 10(4): 482-495. http://dx.doi.org/10.1504/IJGW.2016.079784

Zöldi V, Juhász A, Nagy C, Papp Z, Egyed L (2013): Tick-borne encephalitis and Lyme disease in Hungary: the epidemiological situation between 1998 and 2008. Vector Borne Zoonotic Dis 13(4): 256-265. http://dx.doi.org/10.1089/vbz.2011.0905 
801 Table 2. Calibrated model parameters of Model I. in case of season 1 and season 2

\begin{tabular}{|l|l|l|}
\hline season & 1. & 2. \\
\hline$\alpha$ (axis) & 26.3302 & 123.8382 \\
\hline$\mu$ (mean) & 2.0337 & 4.7124 \\
\hline$\sigma$ (standard deviation) & 0.4804 & 0.0145 \\
\hline$c$ (multiplier) & 82.7165 & 6.8409 \\
\hline$d$ (difference) & 0.0000 & 0.4931 \\
\hline
\end{tabular}

803 Table 3. Calibrated weight factors $\left(\omega_{\mathrm{i}}\right)$ of Model II, where $\mathrm{i}$ is the ordinal number of the 804 weeks of the previous one year period, the sum of the weights, and the sum of squared 805 errors of prediction (SSE) of relative Lyme borreliosis incidence in case of the three 806 model versions. *: the zero value was fixed instead of estimated by calibration. **: 807 weights that seem to refer to the near future instead of the far past (see Chapter 2.3 for 808 details).

\begin{tabular}{|c|c|c|c|}
\hline $\mathrm{i}$ & model A & model B & model C \\
\hline 1 & 0* & $0.0263 * *$ & 0* \\
\hline 2 & 0* & 0 & 0* \\
\hline 3 & 0* & $0,0121 * *$ & 0* \\
\hline 4 & 0* & $0.0163 * *$ & 0* \\
\hline 5 & 0* & $0.0035 * *$ & 0* \\
\hline 6 & 0* & $0.0039 * *$ & 0* \\
\hline 7 & 0* & $0.0036 * *$ & 0* \\
\hline $8-14$ & 0* & 0 & 0* \\
\hline 15 & $0^{*}$ & 0.0029 & 0* \\
\hline 16 & 0* & 0.0008 & 0* \\
\hline 17 & 0* & 0.0003 & 0* \\
\hline 18 & 0* & 0.0088 & 0* \\
\hline 19 & 0* & 0.0007 & 0* \\
\hline 20 & $0^{*}$ & 0.0012 & 0* \\
\hline 21 & 0* & 0.0005 & 0* \\
\hline 22 & 0* & 0.0001 & 0* \\
\hline $23-32$ & $0^{*}$ & 0 & 0* \\
\hline $33-37$ & 0* & 0 & 0 \\
\hline 38 & 0* & 0.0194 & 0 \\
\hline 39 & 0* & 0.0035 & 0.0025 \\
\hline 40 & $0^{*}$ & 0.0017 & 0.0029 \\
\hline 41 & 0* & 0.0188 & 0 \\
\hline 42 & $0^{*}$ & 0.0076 & 0 \\
\hline 43 & 0* & 0.0022 & 0.0991 \\
\hline 44 & 0.0062 & 0.0224 & 0 \\
\hline 45 & 0.0150 & 0.0502 & 0.0001 \\
\hline 46 & 0.0182 & 0.1106 & 0.1328 \\
\hline 47 & 0.0328 & 0.0674 & 0.0403 \\
\hline 48 & 0.0607 & 0.1067 & 0.1130 \\
\hline
\end{tabular}




\begin{tabular}{|l|l|l|l|}
\hline 49 & 0.1152 & 0.0656 & 0.0514 \\
\hline 50 & 0.2162 & 0.1308 & 0.1476 \\
\hline 51 & 0.3463 & 0.1866 & 0.1813 \\
\hline 52 & 0.1947 & 0.1470 & 0.2213 \\
\hline sum of $\omega$ & 1.0053 & 1.0216 & 0.9923 \\
\hline SSE & 12.2184 & 1.9732 & 1.8191 \\
\hline
\end{tabular}

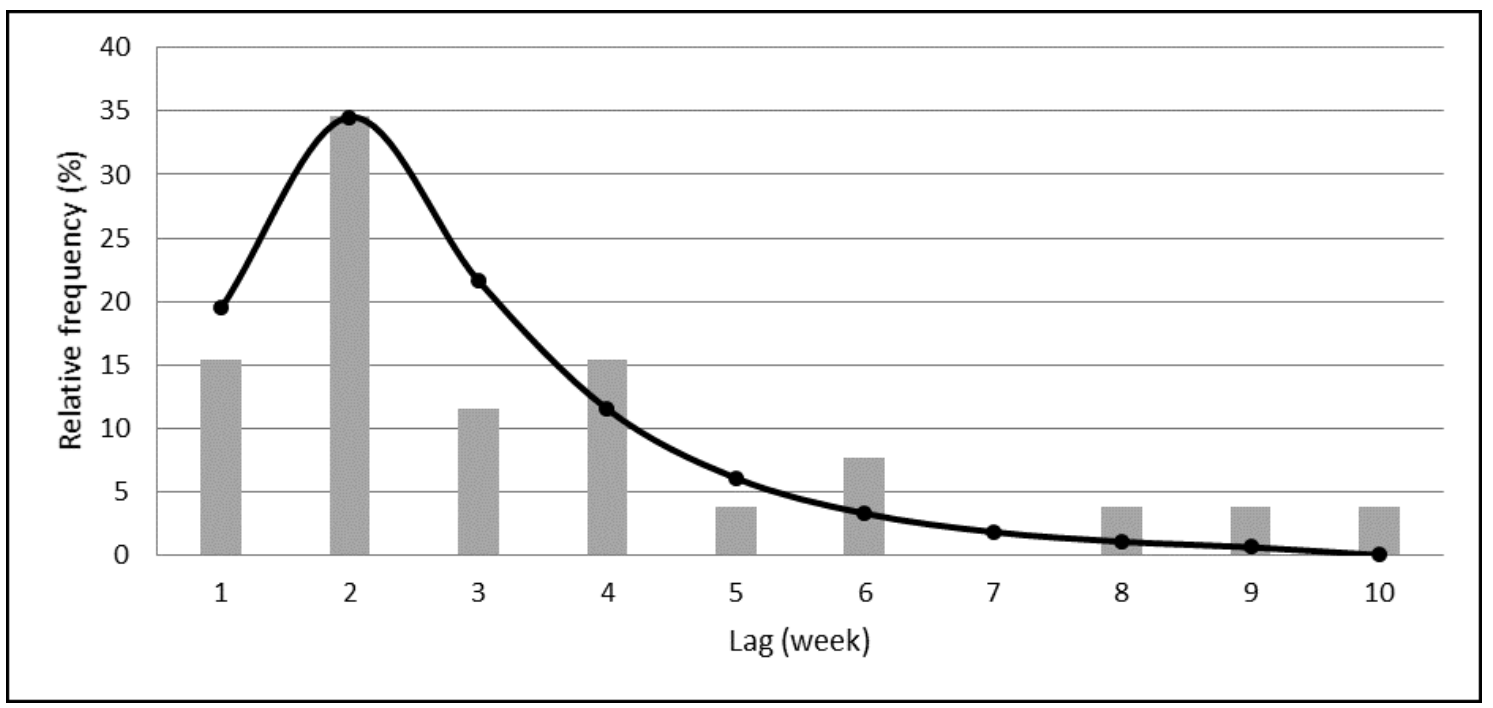

\section{FIGURES}

810 Figure 1. Relative frequency (\%) of observed (gray columns) and modeled (black line) 811 lags between tick bites and onsets of the early manifestation form
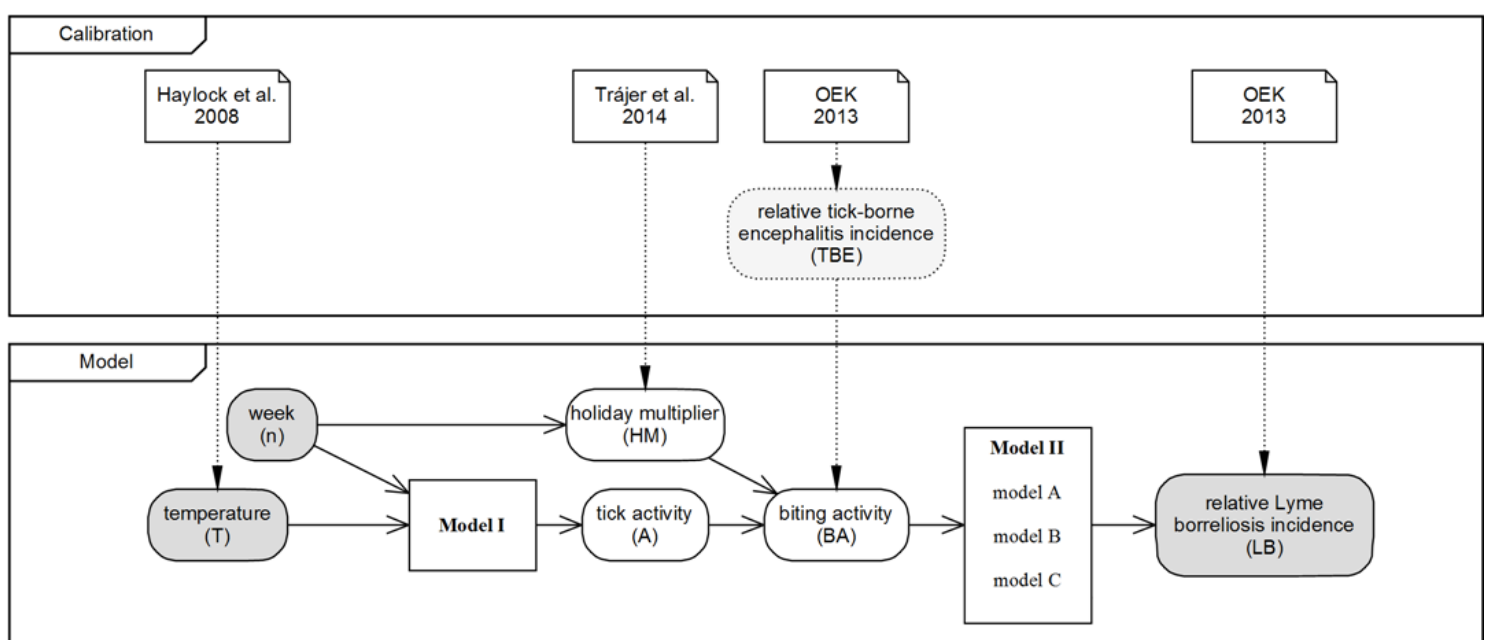

813 Figure 2. The model and its calibration. Input and output parameters are filled with gray 814 color. Although Model I and Model II follow each other sequentially, they form two 815 parts of the framework that can be used independently from each other. 'Model A', 816 'model B' and 'model $\mathrm{C}$ ' are the three alternative versions of Model II. 


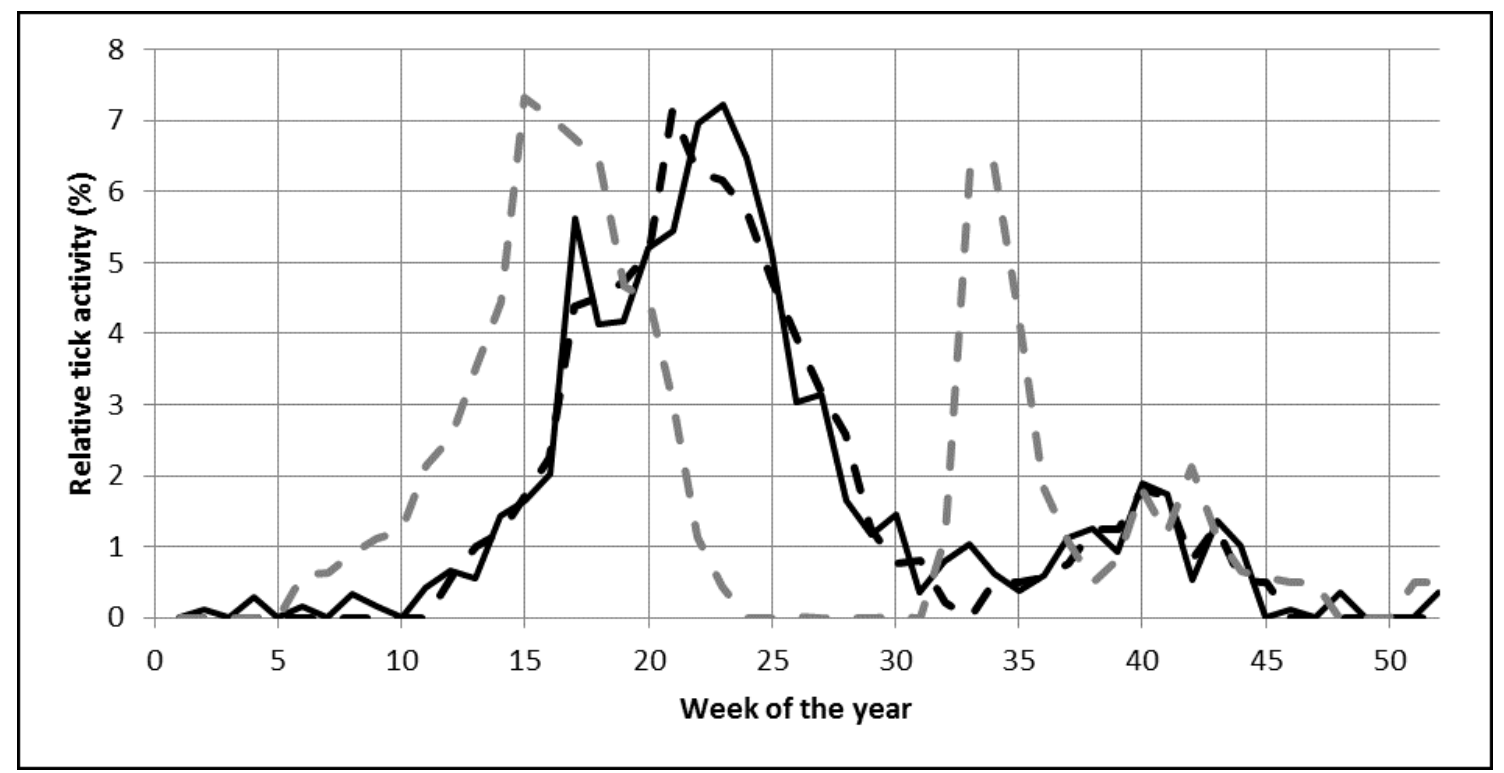

818 Figure 3. Annual distribution of relative tick biting activity (BA; \%) calculated from the 819 calibration dataset (black continuous line), predicted for the reference period (1998820 2008, black dashed line), and predicted for the future period (2081-2100, gray dashed 821 line)

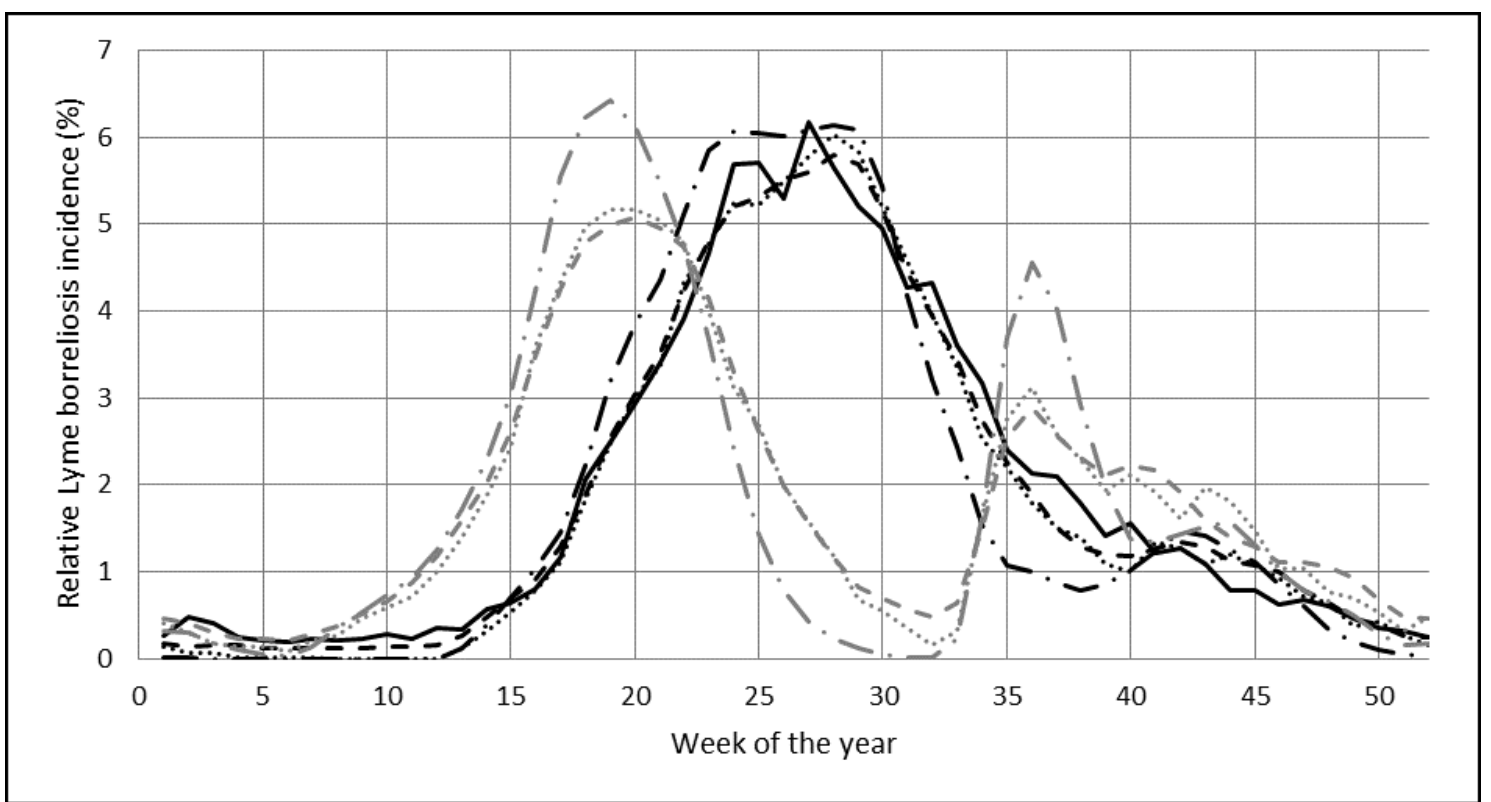

823 Figure 4. Observed (continuous line) and predicted (non-continuous lines) annual 824 distribution of relative Lyme borreliosis incidence (LB; \%) in the reference period 825 (1998-2008, black lines) and in the future period (2081-2100, gray lines), according to 826 model A (dash-dot lines), model B (dashed lines), and model C (dotted lines) 